PACS: 47.45.Ab; 47.50.Cd; 61.20.Ja; 64.70.F; 68.03.-g

V.M. Gun'ko

\title{
MODELLING OF EVAPORATION OF CLUSTERS AND NANODROPLETS OF ORGANIC MOLECULES USING QUANTUM CHEMICAL AND THE KINETIC GAS THEORY METHODS
}

\author{
Chuiko Institute of Surface Chemistry of National Academy of Sciences of Ukraine \\ 17 General Naumov Str., Kyiv, 03164,Ukraine, E-mail:vlad_gunko@ukr.net
}

The evaporation rate $(\gamma)$ of $n$-alkanes $C_{8}-C_{27}$ from molecular clusters and nanodroplets is analysed using the quantum chemical solvation model (SMD) and the kinetic gas theory, assuming that the system is in a state of thermodynamic equilibrium (i.e. evaporation and condensation rates are equal). The droplet size, liquid density, evaporation enthalpy and Gibbs free energy of evaporation are calculated over a broad temperature range of 300-640 K. The quantum chemical calculations (SMD/HF or $S M D / B 3 L Y P$ methods with the 6-31G(d,p) basis set) are used to estimate changes in the Gibbs free energy during the transfer of a molecule from a liquid medium (modelled by clusters or nanodroplets) into the gas phase. The kinetic gas theory is used to estimate the collision rate of molecules with clusters/nanodroplets in the gas phase. This rate depends on partial pressures of components, temperature, sizes and masses of molecules and clusters/nanodroplets. An increase in the molecular size of evaporated alkanes from octane to heptacosane results in a strong decrease in the $\gamma$ values.

Keywords: alkane droplet evaporation, Gibbs free energy, evaporation rate, evaporation coefficient, quantum chemical modelling

\section{INTRODUCTION}

Investigations of the droplet evaporation have been stimulated by numerous related industrial, technological, pharmaceutical and environmental applications [1-13]. Pioneering works on the droplet evaporation were focused on water because of practical importance of this process [4-8]. The latter is determined by the temperature behaviour of water (or organic solvents) and organic or inorganic solutes forming droplets of various sizes located in the gas phase or on solid surfaces (e.g. inkjet or 3D polymer printing) [9-12]. The importance of the evaporation process in Diesel engines has been widely discussed [1-3, 13]. These processes have been studied using both experimental methods and theoretical modelling based on a variety of approaches [1-3, 13-17].

The boundary condition for the kinetic region at a droplet surface is controlled by the evaporation coefficient. Its value was calculated with the molecular dynamics (MD) in which the interaction between individual molecules was described by the force field (FF) methods simplifying both inter- and inner-molecular interactions by ignoring electrons per se (i.e. quantum effects were ignored) $[14,15,18-20]$. Alternative quantum mechanical approaches used to analyse the droplet evaporation process were recently developed [21-25].

Most of the evaporation models were originally developed for water droplets. Despite the simplicity of water molecules in comparison with organics, the investigation of water evaporation is complex [4-8] because of strong hydrogen bonds between each atom in water molecules causing clustered water structures (even in liquid water [26]) which can be strongly affected by solutes and co-solvents [26, 27]. These or similar effects are not observed in alkanes because the intermolecular bonds in alkanes are of the van-der-Waals (vdW) type with a predominant role of London dispersion forces [28-30]. Therefore, the clustered structure of alkanes is less probable than that of water, however, is possible. These alkanes features allow a certain simplicity of the modelling, including the application of molecular mechanics (MM) and molecular dynamics methods based on the vdW force field approaches [16, 18-20]. These models 
can be applied to both individual liquids and complex mixtures including a number of compounds which can be evaporated under various conditions [29-36]. However, the MD/FF models used to study evaporation of alkanes could lead to erroneous results. The main sources of these errors are related to the fact that changes in molecular polarisation, electron transfer and ion or radical formation, as well as electron factors at relatively high temperatures are ignored. Temperature increase can lead to strong thermal vibrations of the bonds and changes in the electron density of atoms during vibrational excitations, fast rotations, conformational changes, and collisions between molecules. The electronic effects (enhanced at high temperatures) in intermolecular interactions between evaporated aromatics and organics with polar functionalities, in comparison with alkanes, can result in an increase in the errors in modelling of these systems using $\mathrm{MD} / \mathrm{FF}$, especially if the force fields are calibrated for systems under standard conditions. A complex approach based on quantum chemical estimations of the Gibbs free energies of solvation $\left(\Delta G_{\mathrm{s}}\right)$ and evaporation $\left(\Delta G_{\mathrm{ev}}\right)$ and the kinetic gas theory was applied to analyse evaporation of real-life Diesel fuel clusters and nanodroplets, including a set of alkanes, substituted aromatics and other organics in the $\mathrm{C}_{8}-\mathrm{C}_{27}$ range $[23,24]$.

Such interactions as molecule-molecule, molecule-cluster, and molecule-nanodroplet, depending on temperature, kinetic energy, and orientation of the molecules hitting a droplet surface are analysed here. Detailed analysis of these processes is expected to allow one to develop a better understanding of the underlying physics of the condensation/evaporation processes. The analysis is based on the kinetic gas theory which allows one to apply the model mainly to molecular clusters and nanodroplets [23,24]. Additional theoretical investigations with $a b$ initio, DFT and semiempirical quantum chemical methods are performed to clarify the underlying physics of the evaporation processes of alkanes.

\section{MODELLING METHODS}

Individual molecules, clusters and nanodroplets of alkanes $\mathrm{C}_{8}-\mathrm{C}_{27}$ (including $n$-dodecane as a representative compound) were studied using $a b$ initio (HF/6-31G(d,p)), DFT (B3LYP/6-31G(d,p)) and semiempirical methods (PM6, PM7) implemented in several program packages: Gaussian $09 \quad$ (revision D.01, 2013) [37],
WinGAMESS (version on May 1, 2013) [38, 39], Firefly (version 8.1) [40], and MOPAC 2012 $[41,42]$. The geometry of initial nanodroplets (with 64 or 128 molecules) was optimised using the molecular mechanics program AMMP (modern full-featured molecular mechanics, dynamics and modelling program with the CFF91 or MM+ force field method implemented in the VEGA ZZ program suit, version 3.0.3) [43]. After that, the geometry was optimised using the PM7 or PM6 methods. The HF and DFT methods with the 6-31G(d,p) basis set were applied to smaller systems with 7-8 molecules (molecular clusters). Visualisation of molecular structures was performed with the help of the ChemCraft (version 1.7/382) [44] or GaussView 5.09 [45] programs.

The Gibbs free energy of solvation $\left(\Delta G_{\mathrm{s}}\right)$ was calculated using the solvation model (SMD, universal solvation model based on solute electron density and on a continuum model of the solvent defined by the bulk dielectric constant and surface tensions) developed by Truhlar et al. [46] and implemented in Gaussian 09 and WinGAMESS. $n$-Dodecane was used as a solvent in SMD. The $\Delta G_{\mathrm{s}}$ values were used to estimate the changes in the Gibbs free energy upon evaporation (i.e. transfer of a molecule from the liquid phase into the gas phase where there is no solvation effect and $\left.\Delta G_{\mathrm{s}}=0\right)$.

To study the dynamics of elimination/condensation of molecules from clusters or nanodrops, the dynamic reaction coordinate (DRC) method was applied. In this method, one calculates atomic velocities (i.e. kinetic energy $E_{k}$ ) and potential energy $E_{p}$ of the system and estimates the average temperature from the $E_{k}$ value. After each time step (chosen as $\Delta t=10^{-16} \mathrm{~s}=0.1 \mathrm{fs}$ ), the potential energy of the system is re-calculated using the PM7 method (MOPAC 2012) [41] or HF/6-31G(d,p) (WinGAMESS or Firefly) [38-40]. The trajectories of atoms are calculated using the classical mechanics approach adding the corresponding kinetic energies to atoms and recalculating their velocity and coordinate vectors at each time step. These calculations allow one to model either the removal of a molecule from a cluster or nanodroplet, or its sticking to the cluster or nanodroplet, and to estimate the corresponding changes in the kinetic energy. This approach is useful for studying the interactions of molecules with nanodroplets depending on the orientation of the attacking molecules and the nanodroplet 
surface molecules, as well as the velocities of the attacking molecules.

The following equation for the evaporation rate $\left(\gamma_{\mathrm{i}(i+\mathrm{j})}\right)[21-24]$ was used in the analysis

$\gamma_{i(i+j)}=b_{i j} \frac{p}{k_{B} T n_{0}} \exp \left(\frac{\Delta G_{i+j}-\Delta G_{i}-\Delta G_{j}}{k_{B} T}\right)$,

where $n_{0}$ is the initial number of molecules in a cluster or nanodroplet, $\gamma_{i(i+j)}$ is the evaporation rate of the $i$-th molecule from a cluster (or nanodroplet) $i+j, b_{i j}$ is the collision rate of the $i$-th molecule with the $j$-th molecule (cluster/nanodroplet) [23, 24], $\Delta G_{i+j}, \Delta G_{i}$, and $\Delta G_{j}$ are the Gibbs free energies of formation of the molecules (clusters/nanodroplets) from monomers (molecules) at the reference pressure $p$. If $i$ or $j$ refers to a monomer (in the gas phase) then the corresponding $\Delta G_{\mathrm{i}}$ or $\Delta G_{\mathrm{j}}$ is equal to zero. For other cases, $\Delta G_{i+j}-\Delta G_{i}-\Delta G_{j}$ corresponds to changes in the Gibbs free energy of the system due to attachment of the $i$-th particle to the $j$-th particle. Note that expression (1) describes the actual rate of removal of molecules from the droplet surface, which is equal to the rate of condensation of molecules in the equilibrium state. Expression (1) cannot be used directly for the analysis of evaporation of droplets under Diesel engine-like conditions, in which the system is essentially not in the thermodynamically equilibrium state, but it can be applied to the analysis of some special experiments in which the state is close to thermodynamic equilibrium (quasiequilibrium). It can, however, be used for the analysis of some trends, which are observed in the immediate vicinity of Diesel fuel droplets where the state of the system is expected to be close to that of thermodynamic equilibrium [14-16]. The collision rate between molecules and clusters/nanodroplets is estimated from the kinetic gas theory (KGT), assuming that these structures are in the state of thermodynamic equilibrium [17, 21-24].

The evaporation enthalpy $\left(Q_{\mathrm{ev}}(T)>0\right)$, contributing to $\Delta G_{\mathrm{ev}}$, and the density of liquids $\rho(T)$ as functions of temperature were estimated as described in [47]. Function $\rho(T)$ was used to estimate the size of clusters/nanodroplets at specific temperatures assuming that swelling of a cluster/nanodroplet is related to its decreased density with temperature.

One can assume that the changes in the Gibbs free energy upon evaporation $\left(Q_{e v}(T)-T \Delta S=\Delta G_{\mathrm{ev}}>0\right)$ correspond to the changes in the Gibbs free energy of a molecule upon solvation at temperature $T_{0}=298 \mathrm{~K}$ but with the opposite sign as $\Delta G_{\mathrm{s}, 0}=\Delta H_{\mathrm{s}}-T_{0} \Delta S<0$, i.e. $\Delta G_{\mathrm{s}, 0}=-Q_{e v}\left(T_{0}\right)-T_{0} \Delta S$ at $\Delta H_{\mathrm{s}}=-Q_{e v}\left(T_{0}\right)$. This leads us to the following equation

$$
\Delta G_{e v}(T)=\Delta G_{s, 0}\left(Q_{e v}(T) / \Delta G_{s, 0}+T / T_{0}\left(1+Q_{e v}\left(T_{0}\right) / \Delta G_{s, 0}\right)\right),
$$

where $\Delta G_{\mathrm{s}, 0}$ is the Gibbs free energy of solvation determined using the SMD method under standard conditions. Eq. (2) was derived assuming that the changes in the entropy $(\Delta S)$ with temperature can be ignored.

Under thermodynamic equilibrium, the number of molecules held in the gas phase around liquid droplets at temperature $T$ can be described by the equation analogous to the Langmuir equation of adsorption [48]

$$
\frac{n_{e v, i}}{n_{0}}=\frac{\alpha \frac{p_{i}}{p_{0}} \exp \left(-\Delta G_{e v, i}(T) / k T\right)}{1+\frac{p_{i}}{p_{0}} \exp \left(-\Delta G_{e v, i}(T) / k T\right)},
$$

where $\alpha$ is a constant (determined from the limiting condition at a sufficiently high temperature), $p_{i} / p_{0}$ is the relative partial pressure of the $i$-th evaporated component, $p_{0}$ is the total pressure, $n_{0}$ is the initial number of molecules in the droplet equal to the total number of molecules in liquid and gas phases during the evaporation process.

As mentioned earlier, the above analysis is applicable to the case when gas and liquid are in a state of thermodynamic equilibrium. When this is not the case, the relevance of quantum chemical effects is restricted mainly to the calculation of the evaporation coefficient

$$
\beta=\left(f_{v, \text { out }}-f_{v r}\right) /\left(f_{v s}-f_{v r}\right),
$$

where $f_{v s}$ is the distribution function of molecules leaving the liquid surface, assuming that the evaporation coefficient is equal to unity, $f_{v r}$ is the distribution function of molecules reflected from the droplets. It was assumed that this coefficient is the same for all directions of the evaporated molecules [14, 15]. The values of $\beta$ for $n$-dodecane were estimated based on classical MD simulations [15]. As follows from these simulations, $\beta$ decreases from $0.9-1.0$ at $T / T_{\mathrm{c}}=0.45-0.55$ to 0.25 at $T / T_{\mathrm{c}}=0.75-0.9$, where $T_{\mathrm{c}}$ is the critical 
temperature. Direct reproduction of calculations presented in $[23,24]$ but taking into account the quantum chemical effects does not look feasible at the moment.

\section{RESULTS AND DISCUSSION}

The evaporation rate calculated with Eqs. (1) and (2), a relative number of molecules evaporated from a droplet $\left(n_{\mathrm{ev}} / n_{0}\right)$ in equilibrium state, and a residual number of molecules in a nanodroplet during evaporation $\left(1-n_{\mathrm{ev}} / n_{0}\right) v s$. the nanodroplet diameter and temperature, are shown in Figs. 1,2 and 3, respectively. Parameter $n_{\mathrm{ev}}(T)$ denotes the number of molecules transferred into the vapour phase as a function of temperature, $n_{0}$ is the total number of molecules, assuming that the system is in a state of thermodynamic equilibrium. Limiting condition $n_{\mathrm{e}} / n_{0}=1$, or $1-n_{\mathrm{ev}} / n_{0}=0$, corresponds to complete evaporation of a nanodroplet occurring under equilibrium conditions at a certain temperature. Note that the results for droplets with diameters close to $1 \mu \mathrm{m}$, shown in Figs. 1 and 2, should be treated with caution, as for these relatively large droplets the condition of thermodynamic equilibrium is not likely to hold. An almost linear decrease in the values of $\gamma$ with growing droplet diameters (Fig. 1) can be attributed to the fact that the ratio of volume to surface area of spherical nanodroplets is proportional to nanodroplet diameters.

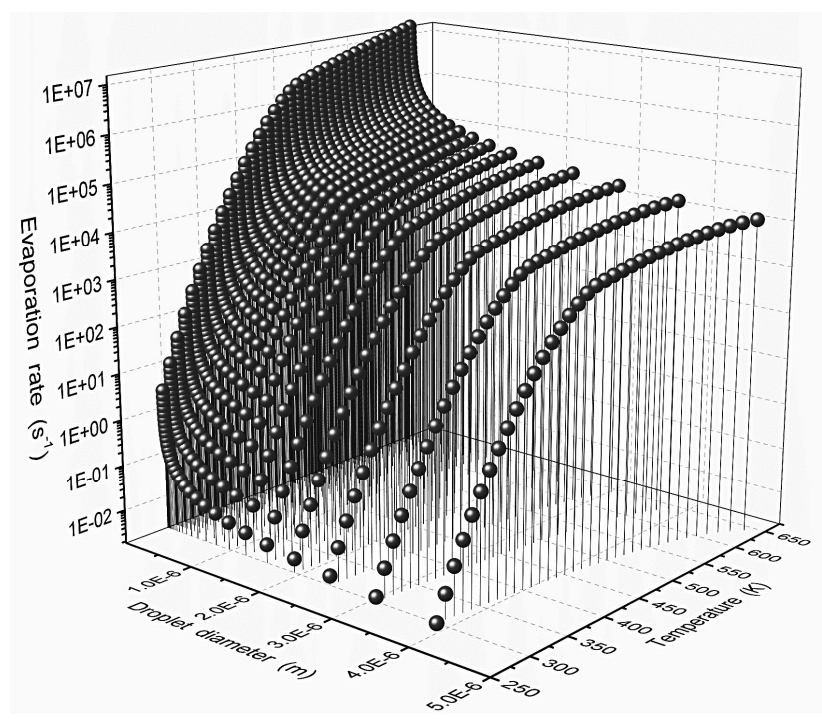

Fig. 1. Evaporation rate vs. temperature and nanodroplet diameter for evaporation of $n$-dodecane molecules from dodecane nanodroplets (HF/SMD/KGT with temperature dependent corrections and $\Delta G_{\mathrm{s}}=-20.5 \mathrm{~kJ} / \mathrm{mol}$ at $300 \mathrm{~K}$ )

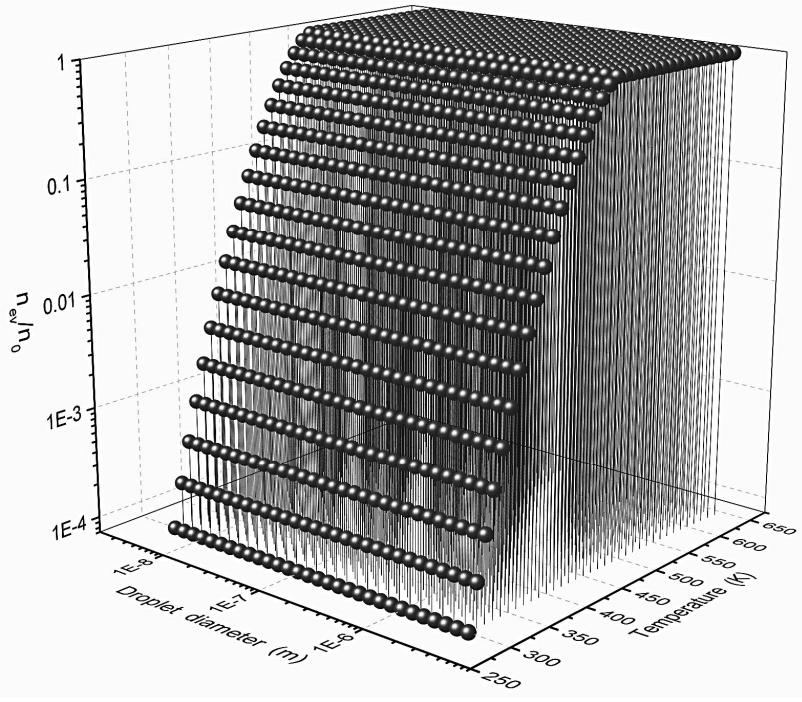

Fig. 2. Relative number of evaporated molecules vs. temperature and nanodroplet diameter for evaporation of $n$-dodecane molecules from $n$-dodecane nanodroplets (HF/SMD/KGT with temperature dependent corrections and $\Delta G_{\mathrm{s}}=-20.5 \mathrm{~kJ} / \mathrm{mol}$ at $300 \mathrm{~K}$ )

Comparison of the Gibbs free energy of solvation of $n$-dodecane obtained by classical force field $\left(\Delta G_{\mathrm{s}}=-30.9 \mathrm{~kJ} / \mathrm{mol}[24]\right)$ and quantum chemical methods $\left(\Delta G_{\mathrm{s}}=-20.5 \mathrm{~kJ} / \mathrm{mol}\right.$ by HF/SMD with WinGAMESS or $-25.5 \mathrm{~kJ} / \mathrm{mol}$ by DFT/SMD with Gaussian 09) shows that the FF result can be closer to the experimental value, $\Delta G_{\mathrm{s}}=-32.8 \mathrm{~kJ} / \mathrm{mol}$, than the SMD ones [46]. However, molecules are evaporated from a droplet surface but not from the bulk solution. At the surface, the number of $n$-dodecane molecule neighbours is about $5 / 8$ of those in the bulk of the droplet for an ordered structure with non-bent molecules (simple estimation gives 32.8.5/8 $=20.5$ ) . Therefore, smaller values of $\Delta G_{i+j}-\Delta G_{i}-\Delta G_{j}=\Delta G_{\mathrm{s}}$ $(-20.5$ or $-25.5 \mathrm{~kJ} / \mathrm{mol})$ is used in Eq. (1) for the calculations of the evaporation rate.

Large $n$-alkanes, such as icosane $\left(\mathrm{C}_{20}\right)$ and heptacosane $\left(\mathrm{C}_{27}\right)$, are more poorly evaporated than smaller $n$-alkanes $\left(\mathrm{C}_{8}, \mathrm{C}_{12}\right)$ from $n$-dodecane medium (Fig. 3). Evaporation of dodecane from $n$-octane medium $\left(\mathrm{C}_{12}{ }^{* * * *}\right)$ occurs more slowly than from dodecane medium $\left(\mathrm{C}_{12}{ }^{*}, \mathrm{C}_{12}{ }^{* *}\right)$. In other words, one can expect that, as a result of evaporation, the gas phase consists mainly of $n$-octane from the $\mathrm{C}_{12}$-in- $\mathrm{C}_{8}$ system, while dodecane remains mainly in nanodroplets at $T<T_{\mathrm{b}, \mathrm{C}_{12}}$ and evaporation of dodecane from octane droplets starts at $T \approx T_{\mathrm{b}, \mathrm{C}_{8}} \approx 399 \mathrm{~K}$. This is 
expected to lead to an increase in mass fractions of compounds with larger molecular masses in complex hydrocarbon droplets during evaporation. Similar changes in droplet composition were observed for aromatics, in which the evaporation rate decreases with increasing molecular weight or the number of aromatic rings in the molecules $[23,24]$. According to Fig. 1, the composition changes can occur faster for smaller droplets. However, changes in $n_{\mathrm{ev}} / n_{0}$ do not depend on the droplet sizes (Figs. 2 and 3).

For small $n$-alkane molecules $\left(\mathrm{C}_{6}\right)$, evaporation of both monomers and dimers was observed, but for larger molecules $\left(\mathrm{C}_{16}\right)$, only monomers were evaporated [49]. This agrees with the modelling results for evaporation of monomers and dimers of various alkanes $[23,24]$. The difference in the evaporation of monomers and dimers can be related not only to the difference in their molecular weight but also to the difference in the corresponding values of $Q_{\mathrm{ev}}, \Delta G_{\mathrm{ev}}$ and $\Delta G_{\mathrm{s}}$.

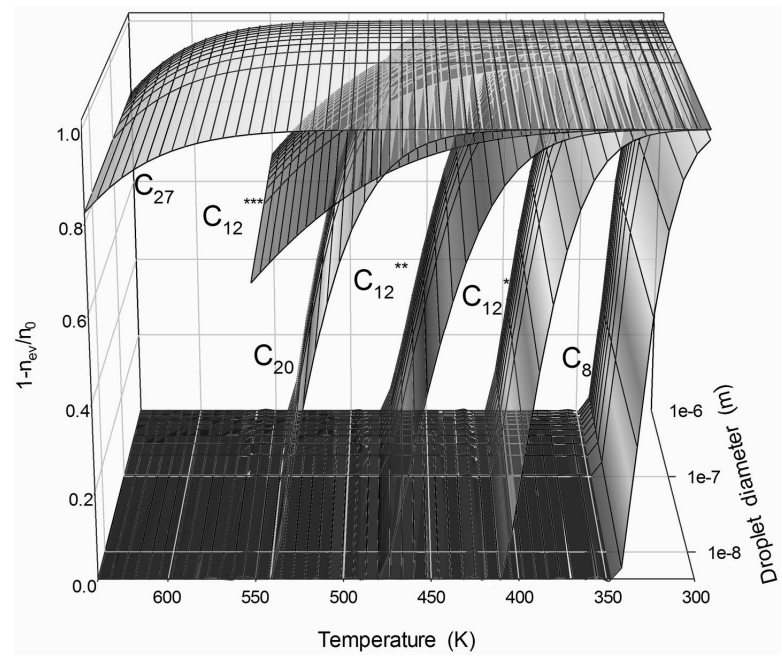

Fig. 3. Relative numbers of molecular residuals in a droplet as a function of temperature and droplet diameter for various $n$-alkanes evaporated from a nanodroplet with $n$-dodecane as a solvent calculated using the SMD/HF/6-31G(d,p)/KGT model (with $-\Delta G_{\mathrm{s}}=11.3\left(\mathrm{C}_{8}\right), 20.5\left(\mathrm{C}_{12}{ }^{*}\right), 25.5$ $\left(\mathrm{C}_{12}{ }^{* * *}\right), 22.4\left(\mathrm{C}_{12}{ }^{* * *}\right.$ in the octane medium), 39.2 $\left(\mathrm{C}_{20}\right)$, and $55.1\left(\mathrm{C}_{27}\right) \mathrm{kJ} / \mathrm{mol}$ at $\left.298 \mathrm{~K}\right)$

Intermolecular interactions of aliphaticaliphatic compounds differ from those of aromaticaromatic ones due to the stronger dispersion and polarisation interactions of aromatics. This can be seen in Fig. 4, where the contributions of various fields for the $n$-dodecane, butylpentylbenzene, and ethylphenanthrene clusters with seven molecules are illustrated.
For alkanes (dodecane in Fig. 4), only dispersion interactions are essential $\approx 91 \%$ for dodecane in the dodecane medium, according to SMD/B3LYP/6-31G(d,p) calculations). These interactions are the main component of the $\mathrm{vdW}$ interactions caused by force between two permanent dipoles (Keesom force), force between a permanent dipole and a corresponding induced dipole (Debye force), and force between two instantaneously induced dipoles (London dispersion force) [28-30]. For aromatics, there are all contributions of $\mathrm{vdW}$ forces and additional polar (positive or negative in Fig. 4) interactions [50]. Therefore, intermolecular interactions between aromatics are stronger than those between alkanes at similar molecular weights. For example, for ethylphenanthrene in the $n$-dodecane or benzene medium, contributions of non-polar components, calculated by SMD/B3LYP/6-31G(d,p), are 78.1 and $77.1 \%$ at $\Delta G_{\mathrm{s}}=-39.9$ and $-44.5 \mathrm{~kJ} / \mathrm{mol}$, respectively. Thus, the relative contribution of non-polar interactions is smaller for aromatics than that for alkenes. Another aspect of the intermolecular interactions is related to ordering-disordering of the supramolecular structures in liquids. Ordered supramolecular structure of molecular clusters/nanodrops affects the interaction energy, since the more ordered the structure, the greater the interaction energy [23, 24].

The positive evaporation enthalpy $Q_{\mathrm{ev}}$ decreases with temperature; e.g. for $n$-dodecane, $Q_{\mathrm{ev}} \approx 60 \mathrm{~kJ} / \mathrm{mol}$ and $18 \mathrm{~kJ} / \mathrm{mol}$ at 300 and $640 \mathrm{~K}$, respectively. This leads to a decrease in the positive Gibbs free energy of evaporation $\left(\Delta G_{\mathrm{ev}}>0\right)$ with temperature as intermolecular interactions in liquids decrease with temperature (liquid density and intermolecular bonds decrease when temperature increases). Therefore, the removal of a molecule from a heated droplet needs less energy than its removal from a cold droplet. The Gibbs free energy of solvation of molecules in liquid is negative $\left(\Delta G_{\mathrm{s}}<0\right)$ and its modulus decreases with temperature due to the above-mentioned effect. The evaporation becomes more difficult when the size of evaporated molecules increases since this size affects the values of $Q_{\mathrm{ev}}$ [46], $\Delta G_{\mathrm{ev}}$ and $\Delta G_{\mathrm{s}}$. For example, when the sizes of $n$-alkane molecules increase, their evaporation from nanodroplets with dodecane as a solvent, calculated using the SMD/KGT model, becomes more difficult (Figs. 3-5) since the values of $\left|\Delta G_{s}\right|$ and $\Delta G_{\mathrm{ev}}$ significantly increase with increasing molecular 
size of organics [23, 24, 47]. Evaporation of $\mathrm{C}_{8}-\mathrm{C}_{12}$ $n$-alkanes from dodecane nanodroplets occurs mainly at $T<T_{\mathrm{b}}=489.5 \mathrm{~K}$ (boiling temperature of dodecane) (Fig. 3). An increase in the predicted values of $\left|\Delta G_{\mathrm{s}}\right|$ for dodecane from $20.5 \mathrm{~kJ} / \mathrm{mol}$ (SMD/HF) to $25.5 \mathrm{~kJ} / \mathrm{mol}$ (SMD/DFT) leads to a shift of the evaporation plot with temperature, as strong dodecane molecule-dodecane medium interaction (i.e. lower $\Delta G_{\mathrm{s}}$ or higher $\left|\Delta G_{\mathrm{s}}\right|$ ) slows down evaporation. The value of $\left|\Delta G_{\mathrm{s}}\right|$ for heptacosane in dodecane is $55.1 \mathrm{~kJ} / \mathrm{mol}$ (SMD/HF/6-31G(d,p)), much higher than that for $\mathrm{C}_{8}-\mathrm{C}_{20}$, and therefore the plot of $\left(1-n_{\mathrm{ev}} / n_{0}\right)$ for $\mathrm{C}_{27}$ shows the maximal shift towards higher temperatures (Fig. 3).

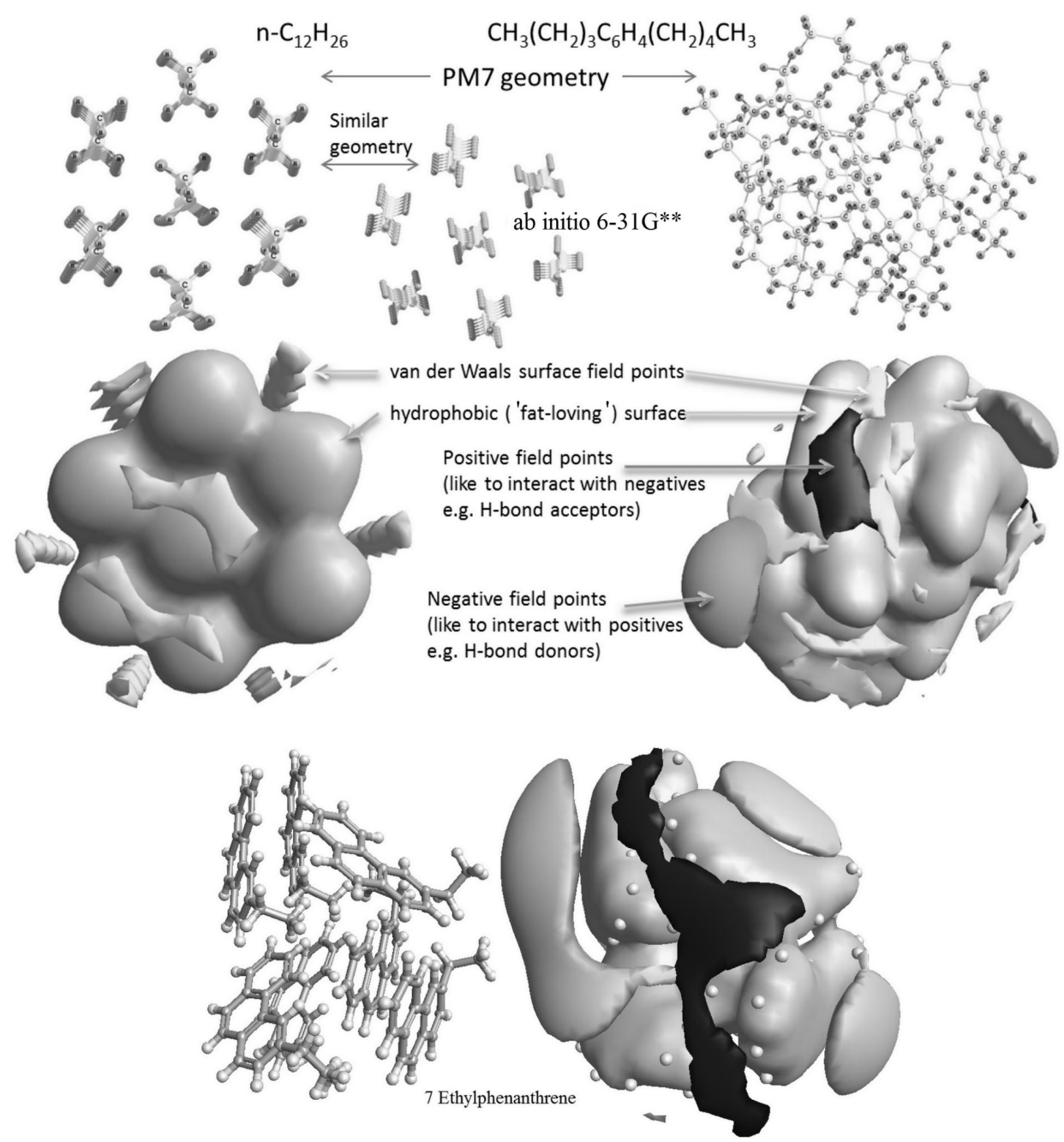

Fig. 4. Fields in clusters with alkanes ( $n$-dodecane) (top left scheme) and aromatics (7 molecules of butylpentylbenzene (top right scheme) or ethylphenanthrene (bottom scheme)) optimised with HF/6-31G(d,p) or PM7 (the fields around molecules were visualized using the TorchLite program (version 10.0.1) [50])

The evaporation rates, expressed in terms of the rate of decrease of the squared droplet diameter if condensation is removed, $\left(k_{\mathrm{ev}}\right)$ versus temperature for droplets with diameters of 14.4 and $64 \mu \mathrm{m}$, are shown in Fig. 5. The plots shown in this Figure are expected to show the trends of $k_{\mathrm{ev}}$ rather than their quantitative characteristics as the validity of the condition of thermodynamic equilibrium for such large droplets could be questionable. As follows from this Figure, an increase in the droplet size leads to an increase in the evaporation rate; for droplets with $d=64 \mu \mathrm{m}, k_{\mathrm{ev}}$ increases with increasing temperatures. Similar effects were observed in the experiments, the results of which were described in [51]. In these experiments the evaporation rate of dodecane droplets was 
measured in a nitrogen atmosphere at $0.2 \mathrm{MPa}$ at various temperatures.

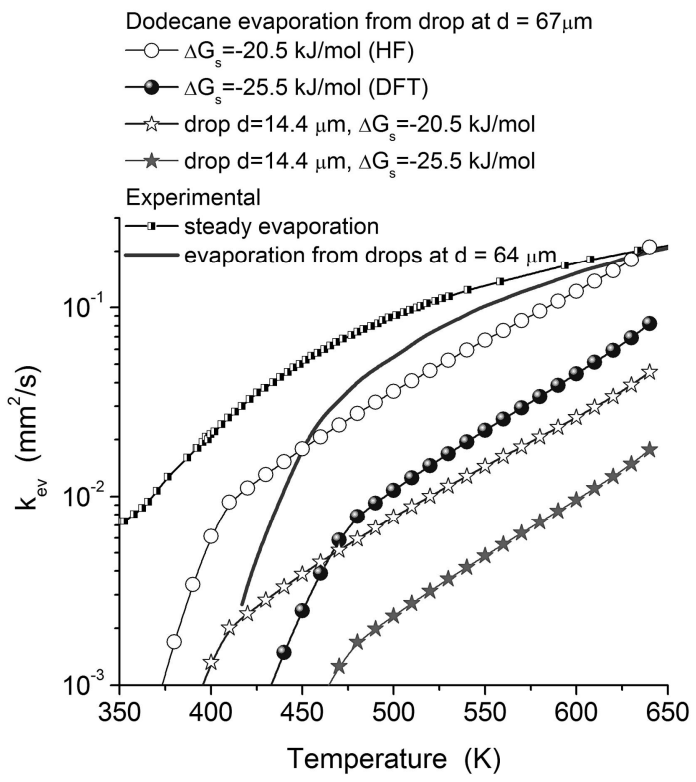

Fig. 5. The rates of evaporation of $n$-dodecane droplets with the initial diameters 14.4 and $67 \mu \mathrm{m}$ and at two initial Gibbs free energies of solvation and experimental data on dodecane evaporation [51]

The average kinetic energy of the translational motion of the whole molecules (estimated as $\left.E_{\mathrm{k}}=3 k_{\mathrm{B}} T / 2\right)$ in the temperature range $300-1200 \mathrm{~K}$ $\left(E_{\mathrm{k}}=3.8-15.1 \mathrm{~kJ} / \mathrm{mol}\right)$ is smaller than the interaction energy of molecules in the liquid state at $300 \mathrm{~K}\left(\Delta G_{\mathrm{s}}=-25.5 \mathrm{~kJ} / \mathrm{mol}\right.$, as predicted by SMD/B3LYP/6-31G(d,p)). Therefore, the evaporation of $n$-dodecane at $300-350 \mathrm{~K}$ is very slow (Figs. 2 and 3). However, heating of nanodroplets at $T>400 \mathrm{~K}$ (Figs. 1-5) leads to a decrease in the interaction (potential) energy between molecules and an increase in the average kinetic energy of the molecules (vide infra). Therefore, the probability that gas-phase molecules will stick to droplets is expected to decrease with increasing temperature due to two factors: increase in the average kinetic energy of molecules and decrease in the average interaction energy of the molecules (the modulus of the potential energy decreases). The molecule/nanodroplet scattering and evaporation of molecules from nanodroplets are determined by equilibrium conditions and the weight and diameters of nanodroplets, but do not depend on the kinetic characteristics of attacking molecules. However, the values and directions of velocities of attacking molecules relative to nanodroplet surfaces, as well as orientation of molecules at droplet surfaces, are expected to affect the collision processes, leading to scattering or condensation. Additionally, evaporative cooling can reduce temperatures of nanodroplet surfaces which can result in an increase in condensation of molecules from the gas phase. This is consistent with experimental data [51].

In our analysis so far, the results of interaction of molecules with nanodroplets, determined by the evaporation/condensation rate (Eq. (1)), were obtained assuming the equilibrium state of the system in which the collisions between molecules and nanodroplets are described using the kinetic gas theory, regardless of the nature of these collisions. In what follows, the details of the collision processes are investigated using the dynamic reaction coordinate (DRC) method. The DRC results can elucidate the interaction mechanism of a molecule with cluster/nanodroplet depending on the kinetic characteristics and temperature of the system. These characteristics refer to scattering or sticking of the molecules. In the DRC calculations, the total kinetic energy is partitioned into the kinetic energy of random thermal bond vibrations and rotations and the kinetic energy of the translational motion of the whole molecules. In our analysis, the DRC method was applied to study the dependence of sticking/scattering of $n$-dodecane molecules on their angles of attack, kinetic energy (temperature), and cluster/nanodroplet size. The DRC calculations were performed for molecules interacting with a cluster ( 7 molecules) or a nanodroplet (64 or 128 molecules) of dodecane molecules (Figs. 6-8).

Figs. 6 and 7 show that at large angles of attack, a molecule is absorbed by a cluster or nanodroplet even of relatively small size $(d=2-7 \mathrm{~nm})$ if the kinetic energy is low and the attacking molecule is not oriented exactly towards one of the surface molecules (but rather between neighbouring surface molecules) (Fig. $6 b$ ). At $\Theta \approx 1^{\circ}$ (Fig. 6a) an almost perfectly elastic collision was observed if the molecule had relatively high velocity (kinetic energy $\sim 10 \mathrm{~kJ} / \mathrm{mol}$ or larger) and was oriented directly towards one of the surface molecules.

In the DRC calculations (Figs. 6-8), the kinetic energy of the molecules in the clusters or nanodroplets was low and thermal vibrations and bond rotations corresponded to $300-400 \mathrm{~K}$. At the same time, the kinetic energy of the attacking molecule was high (its effective temperature was in the range 500-1200 K). 

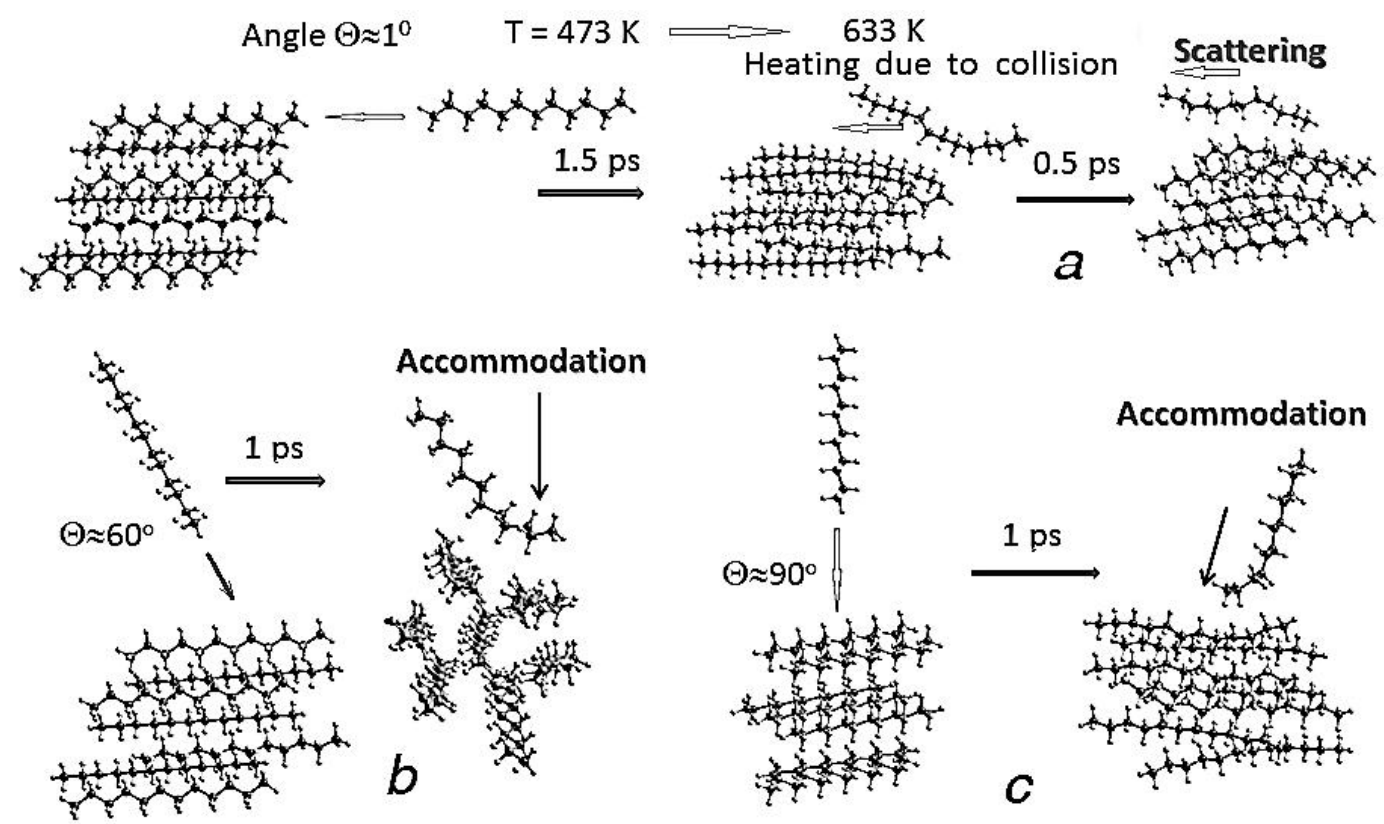

Fig. 6. Interaction of a dodecane molecule (hot, temperature $\sim 1100 \mathrm{~K}$ ) with a cluster of seven dodecane molecules (initial temperature $473 \mathrm{~K}$; it increases due to the interaction with a hot molecule) at the angles of attack $\Theta \approx(a) 1$, (b) 60 and (c) $90^{\circ}$

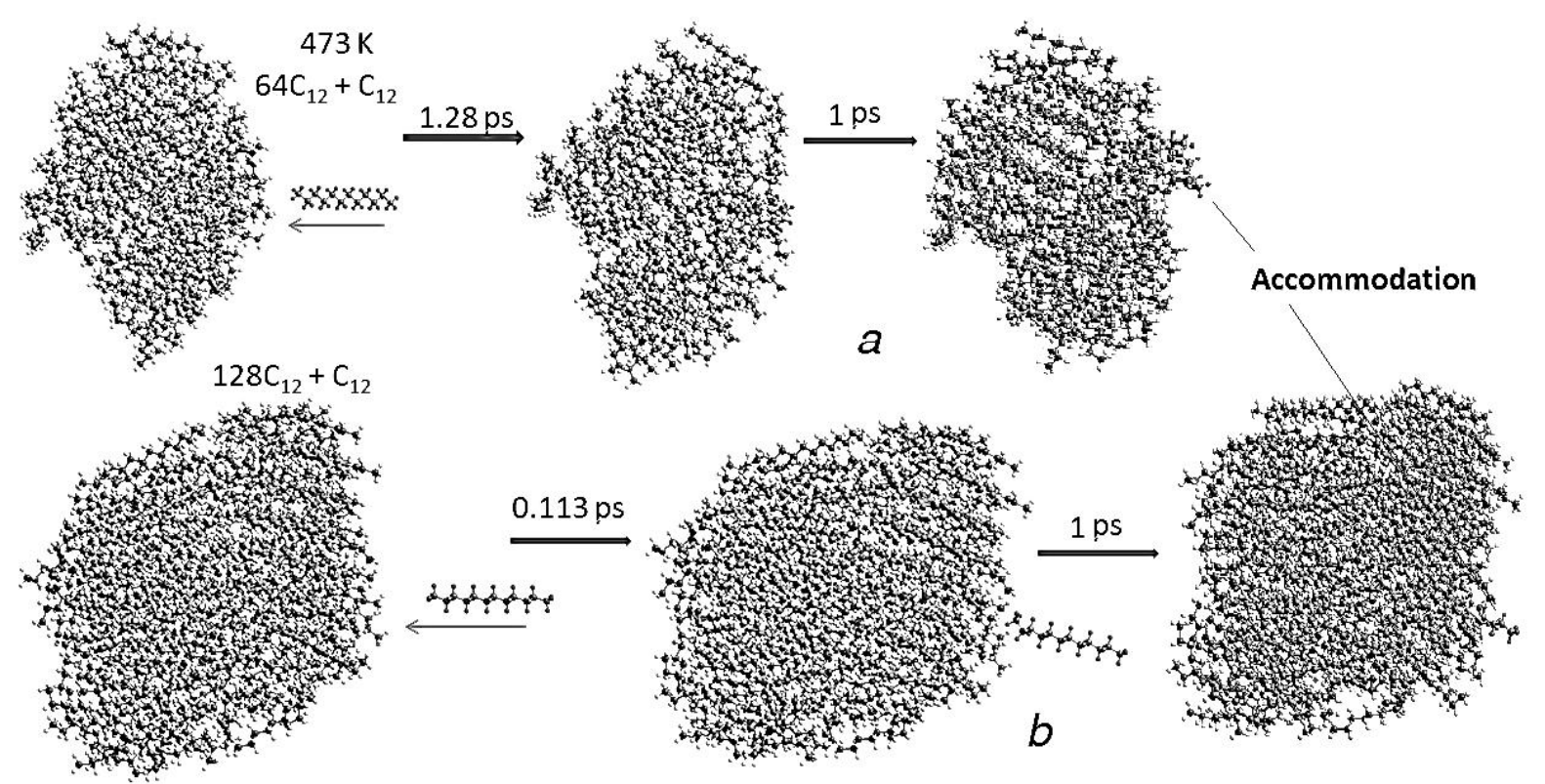

Fig. 7. Interaction of a dodecane molecule (hot, temperature $\sim 1100 \mathrm{~K}$ ) with clusters (initial temperature $\sim 473 \mathrm{~K})$ of $(a)$ 64 and $(b) 128$ dodecane molecules at the angle of attack $\Theta \approx 90^{\circ}$ 

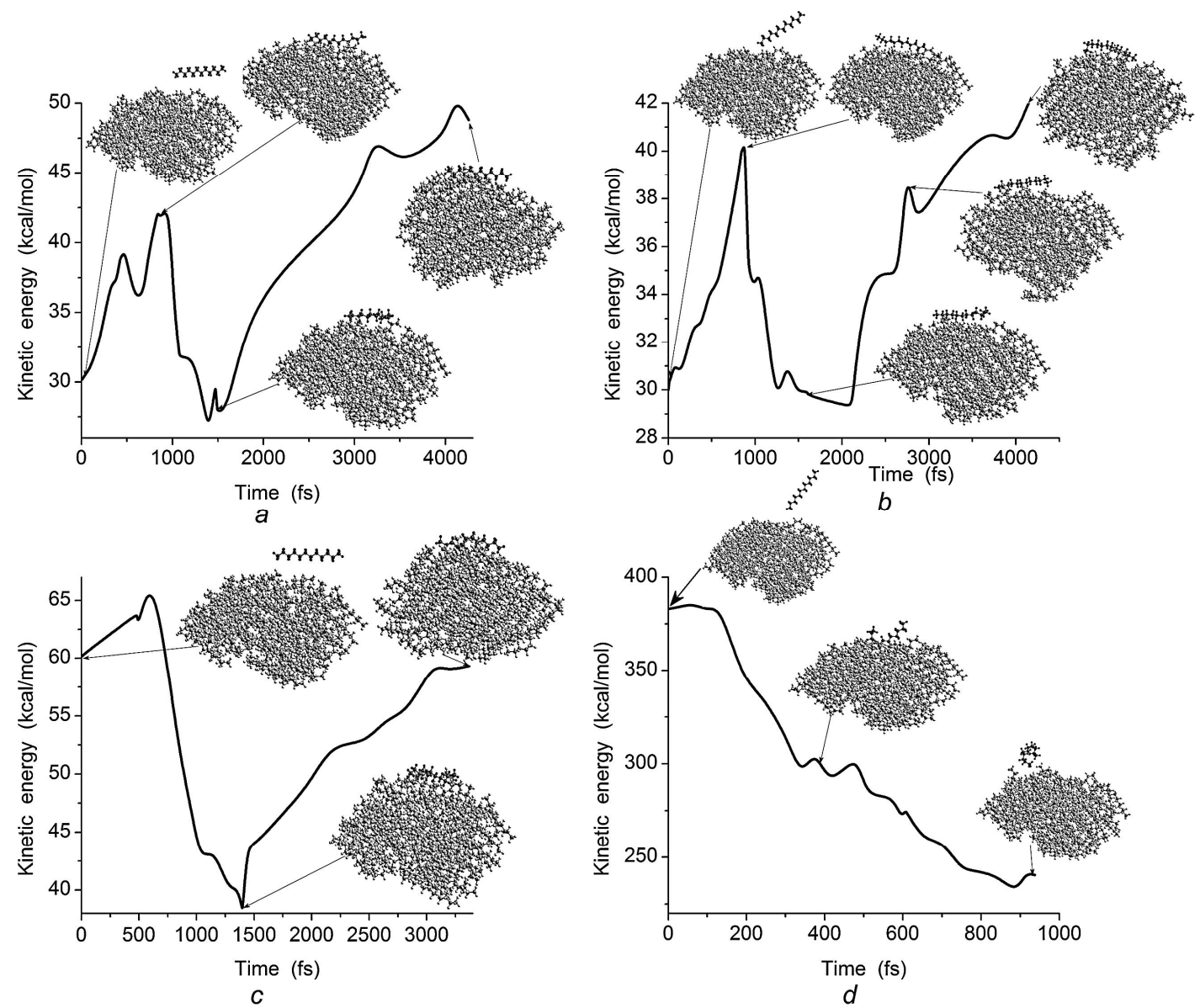

Fig. 8. Changes in the kinetic energy of the attacking dodecane molecule during its interaction with a nanodroplet of 64 dodecane molecules at various angles of attack: (a) 5, (b) 40, (c) 5, and (d) $45^{\circ}$, and various initial kinetic energies: $(a, b) 125.5$, (c) 251, and $(d) 1602 \mathrm{~kJ} / \mathrm{mol}$ (these kinetic energies correspond to the energies of both translational motion and thermal vibrations or rotations)

At relatively low kinetic energies of attacking molecules $(T<450 \mathrm{~K})$, the sticking (condensation) is expected to dominate over the scattering of molecules (Fig. $8 a-c$ ), i.e., these molecules remain on the droplet surface following collisions after a certain time $(3.7-4.5 \mathrm{ps}$ in Fig. $8 a-c)$. A significant increase in the kinetic energy of the attacking molecule after a minimum at $1.5-2 \mathrm{ps}$ (Fig. $8 a-c$ ) is related to reorganisation of the nanodroplet after strong interaction with the attacking molecule accompanied by a decrease in its potential energy. An increase in the kinetic energy of the attacking molecules at the initial stage of the interactions (curves in Fig. $8 a-c$ ) is related to the reduction of the potential energy of the system when an attacking molecule approaches the cluster/nanodroplet. Then the kinetic energy of the attacking molecule decreases as it is transferred into the potential energy of the molecules in the cluster/nanodroplet.
During the interaction of the high-energy scattered molecule with the cluster/nanodroplet (Fig. $8 d$ ), the kinetic energy of the system per molecule, $E_{\mathrm{k}}=24.7 \mathrm{~kJ} / \mathrm{mol}$ (including both translational motion and thermal vibrations/rotations), was close to $\left|\Delta G_{\mathrm{s}, 0}\right|=25.5 \mathrm{~kJ} / \mathrm{mol}$ at $298 \mathrm{~K}$ or $Q_{\mathrm{ev}}=26.6 \mathrm{~kJ} / \mathrm{mol}$ at $610 \mathrm{~K}$. The kinetic energy of the system strongly decreases as the kinetic energy of the attacking molecule is transferred into the potential energy of the nanodroplet. Note that the interaction of a "hot" molecule $\left(T>T_{\mathrm{b}}\right)$ with a "cold" nanodroplet $\left(T<T_{\mathrm{b}}\right)$ leads to a decrease in the molecule's energy and a corresponding increase in the nanodroplet's energy, and then to the situation when the energies (temperatures) of both become close. The use of nanodroplets at high temperatures is restricted by their fast decomposition (Fig. 9). The results of our calculations suggest that in the case where the attacking molecule is parallel or 
almost parallel to the droplet surface, the interaction between this molecule and the surface molecules takes place with many $\mathrm{CH}$ groups. Therefore, this interaction is expected to be maximal; i.e. the potential energy can be minimal at a certain distance between the molecule and the surface. Then, with the molecule approaching the surface, the potential energy grows strongly and the kinetic energy of the molecule decreases. This multi-centred interaction provides faster dissipation of the excessive kinetic energy of a hot attacking molecule in the droplet in comparison with a unicentred interaction (spear-type attack). Therefore, the probability of an attacking molecule sticking to the droplet is greater in the case of molecules approaching parallel or almost parallel to the droplet surface than for molecules attacking the droplet surface at high attacking angles.

The process of the interaction between the attacking molecules and nanodroplets (with the initial geometry shown in Fig. $9 a$ ), heated at $T=273,373,489.5$, and $773 \mathrm{~K}$ for $5 \mathrm{ps}$, is shown in Figs. $9 b-e$. In all cases, the initial kinetic energies of attacking molecules are equal to those of molecules in nanodroplets, and the nanodroplets are located in free unbounded space. As follows from Fig. $9 b, c$, the nanodroplet structures remain stable at 273 and $373 \mathrm{~K}$ according to $\mathrm{MD} / \mathrm{FF}$ $(\mathrm{MM}+)$ calculations. In these cases, relatively cool attacking molecules are condensed at the nanodroplet surface, i.e. the condensation coefficient is close to unity. At $n$-dodecane boiling temperature $(489.5 \mathrm{~K})$, the nanodroplet starts to disintegrate into small clusters and individual molecules (Fig. $9 d$ ). This decomposition of the nanodroplet into monomolecular and clustered fragments becomes more intensive at $773 \mathrm{~K}$ (Fig. $9 e$ ).

To model the behaviour of larger structures and to analyse the evaporation process, a nanodroplet is located in a box with periodic boundary conditions at the sides of the box (Fig. 9f). The MD/FF calculations of such an dodecane system at $473 \mathrm{~K}$ show only slow removal of individual molecules. This result indicates that the condensation process can be less effective at $T$ close to the boiling temperature than at lower temperatures. This corresponds to a decrease in the value of the condensation coefficient.
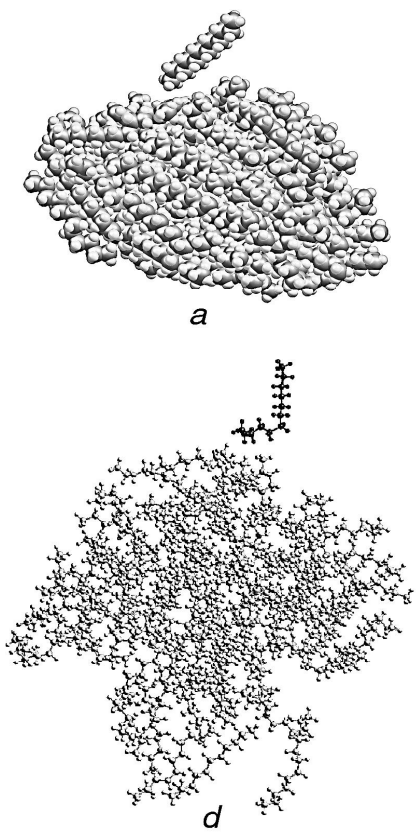
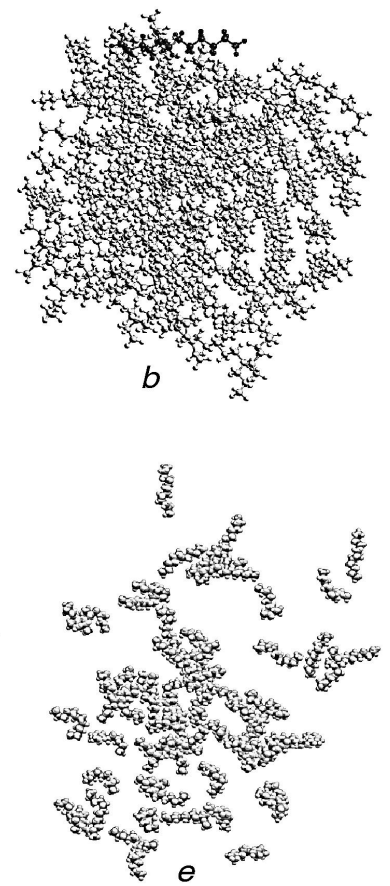
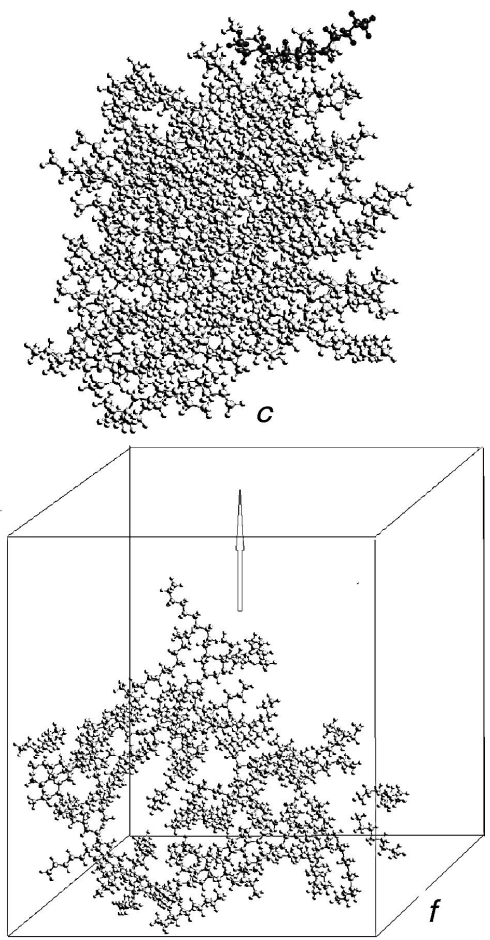

Fig. 9. Interaction of a dodecane molecule with a nanodroplet of $64 \mathrm{C}_{12}:(a)$ initial geometry optimised with $\mathrm{MM}+$; the system is heated (MD/FF(MM+)) for 5 ps at $(b) 273,(c) 373,(d) 489.5$ (boiling temperature, $T_{\mathrm{b}}$ ), $(e) 773 \mathrm{~K}$ (with the value of $E_{\mathrm{k}}$ of the attacking molecule corresponding to the temperature of the system) in an infinite space and $(f)$ in a box with periodic boundary conditions at the sides of the box, approximating a flat free surface at $473 \mathrm{~K}$ for the heating period $3.5 \mathrm{ps}$ 
Thus, the comparison of the mobility of molecules in nanodroplets in free space (Fig. $9 a-e$ ) and confined space (Fig. $9 f$ ) shows that the mobility of molecules is expected to reduce when the size of droplets increases. We can anticipate that the mechanisms of evaporation of large droplets (microdroplets) and nanodroplets are likely to involve rather different processes. In the case of microdroplets, individual $\mathrm{C}_{12}$ molecules are evaporated from their surfaces, while in the case on nanodroplets, they are disintegrated into clusters and individual molecules. This difference is attributed to different numbers of neighbouring molecules in clusters, nanodroplets and microdroplets, i.e. different numbers of intermolecular bonds per molecule, which should be broken to enable the removal (evaporation) of these structures from the nano- and microdroplets. As follows from our analysis, the accommodation time for the dynamic (DRC) interaction of a hot molecule $(T>500 \mathrm{~K})$ with a nanodroplet is rather short. This time can be estimated using the Frenkel formula $[48,52]$ for accommodation time (lifetime) of a molecule at a surface

$$
\tau=\tau_{0} \exp \left(E / k_{B} T\right),
$$

where $\tau_{0} \approx 0.1-1.0 \mathrm{ps} \quad$ (time of molecular vibration), and $E$ is the interaction energy.

The value of $E$ can be estimated as $E=Q_{\mathrm{a}}-E_{\mathrm{k}}$, where $Q_{\mathrm{a}}$ is the enthalpy of adsorption of a molecule at a nanodroplet surface. If $Q_{\mathrm{a}}=E_{\mathrm{k}}$ in Eq. (5) then $\tau \approx \tau_{0}$, but structures (Fig. $8 a-c$ ) are characterized by $\tau>\tau_{0} \approx 0.1-1.0$ ps, i.e. $Q_{\mathrm{a}}>E_{\mathrm{k}}$, however, at $\tau \approx 0.4$ ps and $Q_{\mathrm{a}}<E_{\mathrm{k}}$ (Fig. $8 d$ ). If we assume that $Q_{\mathrm{a}} \approx \Delta G_{\mathrm{e}}, \quad$ then at $420 \mathrm{~K}$, $\Delta G_{\mathrm{e}} \approx 8.2 \mathrm{~kJ} / \mathrm{mol}, \quad E_{\mathrm{k}} \approx 5.2 \mathrm{~kJ} / \mathrm{mol}, \quad$ and $\tau \approx 0.24-2.4$ ps. If the accommodation time is longer than $0.24-2.4 \mathrm{ps}$ at $420 \mathrm{~K}$, then we can assume that a molecule is condensed at a nanodroplet surface.

As follows from the above-mentioned results, the condensation coefficient (i.e. the attachment of attacking molecules to a droplet surface) is expected to decrease with increasing temperatures of attacking molecules due to the increasing probability of scattering of attacking molecules at the clusters'/nanodroplets' surface. Also, the lifetime of the "surface" molecules exponentially decreases with temperature and the Gibbs free energy of evaporation decreases when the temperature of nanodroplets increases. These processes make additional contributions to the reduction of the condensation/evaporation coefficient with temperature. This decrease in the evaporation coefficient agrees with the prediction of the classical theory based on the MD simulations of dodecane molecules $[15,16]$.

\section{CONCLUSIONS}

The evaporation/condensation processes in molecular clusters and nanodroplets of $n$-alkane molecules in the $\mathrm{C}_{8}-\mathrm{C}_{27}$ range are investigated using quantum chemical methods (SMD/HF or SMD/B3LYP with the 6-31G(d,p) basis set). These methods were used to estimate changes in the Gibbs free energy during the transfer of a molecule from a liquid medium (clusters or nanodroplets) into the gas phase.

Evaporation rate $(\gamma)$ is analysed using the above-mentioned quantum chemical solvation model (SMD) and the kinetic gas theory, assuming that the system is in a state of thermodynamic equilibrium (evaporation and condensation rates are equal). The evaporation rate is shown to decrease with increasing cluster/nanodroplet diameter and decreasing temperature. The relative number of evaporated molecules, however, does not depend on cluster/nanodroplet diameters, and increases with increasing temperature. At certain temperatures, the clusters/nanodroplets are expected to fully evaporate. The relative number of residual molecules in clusters/nanodroplets for $n$ alkanes in the range $\mathrm{C}_{8}-\mathrm{C}_{27}$ is shown to increase with temperature and the carbon numbers in the molecules. Thus, the evaporation process of a mixture of $n$-alkanes is expected to lead to increased concentration of heavy $n$-alkanes in droplets.

The details of the collision processes of molecules with nanodroplets were investigated using the DRC method. The DRC calculations were performed for molecules interacting with a cluster (7 molecules) or a nanodroplet (64 or 128 molecules) of dodecane molecules.

It is shown that at large angles of attack $\left(45-90^{\circ}\right)$, a molecule is absorbed by a cluster or nanodroplet even of relatively small diameter $(d=2-7 \mathrm{~nm})$, if the kinetic energy is low (corresponding to $T<473 \mathrm{~K}$ ) and the attacking molecule is not headed directly toward one of the surface molecules. The probability of the attacking molecule sticking to a droplet is maximal if the molecular plane is parallel or almost parallel to the droplet surface as this corresponds to multipoint interactions of relatively long dodecane molecule 
with the droplet surface. If the kinetic energy of the attacking molecules is high $\left(T>T_{\mathrm{b}}\right)$ then it is expected that it will scatter and be removed from the cluster/nanodroplet surface. Moleculenanodroplet interaction results (sticking or scattering) depend on the kinetic energy (temperature) and orientations of the attacking molecule and surface molecules.

It is shown that the mechanisms of evaporation of microdroplets and nanodroplets are likely to involve rather different processes. In the case of microdroplets, individual $\mathrm{C}_{12}$ molecules are evaporated from their surfaces, while in the case of nanodroplets they can be disintegrated into clusters and individual molecules. The decrease in the evaporation/condensation coefficient with temperature, predicted by our analysis, agrees with the prediction of the classical theory based on the MD simulations of $n$-dodecane molecules.

Acknowledgement. The author is grateful to the EPSRC (UK) (grant EP/J006793/1) for financial support.

\title{
Моделювання випаровування кластерів і нанокраплин органічних молекул методами квантової хімії та кінетичної теорії газів
}

\author{
В.М. Гунько \\ Інститут хімії поверхні ім. О.О. Чуйка Національної академії наук України \\ вул. Генерала Наумова, 17, Київ, 03164, Украӥна, vlad_gunko@ukr.net
}

Швидкість випаровування $(\gamma)$ молекул п-алканів в інтервалі $C_{8}-C_{27}$ з молекулярних кластерів $i$ нанокраплин проаналізовано з використанням квантовохімічної сольватачійної моделі (SMD) $i$ кінетичної теорії газів у припущенні, щяо система перебуває в термодинамічній рівновазі (тобто швидкості випаровування та конденсаиії однакові). Розміри краплинок, густини рідин, ентальпію випаровування та вільну енергію Гіббса розраховували при 300-640 К. Квантовохімічні розрахунки (методами SMD/HF або SMD/B3LYP з базисом 6-31G(d,p)) використовували для оцінки змін вільної енергї̈ Гіббса при перенесенні молекули з рідкого середовища (кластери та нанокраплинки) у газову фазу. Кінетичну теорію газів було використано для оиінки швидкості зіткнення молекул з кластерами/нанокраплинками у газовій фазі. Ця швидкість залежсить від париіального тиску, температури, розмірів і маси молекул та кластерів/нанокраплинок. Зростання молекулярних розмірів алканів, що випаровуються, з октану до гептакозану призводить до значного зменшення величини $\gamma$.

Ключові слова: випаровування краплин алканів, вільна енергія Гіббса, швидкість випаровування, коефіцієнт випаровування, квантовохімічне моделювання

\section{Моделирование испарения кластеров и нанокапель органических молекул методами квантовой химии и кинетической теории газов}

\author{
В.М. Гунько
}

Институт химии поверхности им. А.А. Чуйко Национальной академии наук Украинь ул. Генерала Наумова, 17, Киев, 03164, Украина, vlad_gunko@ukr.net

Скорость испарения ( $\gamma)$ молекул n-алканов в интервале $C_{8}-C_{27}$ из молекулярных кластеров и нанокапель проанализировано с использованием квантовохимической сольватационной модели $(S M D)$ и кинетической теории газов в предположении, что система находится в термодинамическом равновесии (т.е. скорости испарения и конденсации одинаковы). Размеры капелек, плотности жидкостей, энтальпию испарения и свободную энергию Гиббса рассчитывали 
при 300-640 К. Квантовохимические расчеты (методами SMD/HF или SMD/B3LYP с базисом 6-31G(d,p)) использовали для оиенки изменений свободной энергии Гиббса при переносе молекуль из жидкой среды (кластеры и нанокапли) в газовую фазу. Кинетическую теорию газов использовали для оценки скорости столкновений молекул-кластеров/нанокапель в газовой фазе. Эта скорость зависит от парииального давления, температуры, размеров и массы молекул и кластеров/нанокапель. Увеличение молекулярных размеров испаряемых алканов от октана до гептакозана приводит к значительному уменьшению величины $\gamma$.

Ключевые слова: испарение капель алканов, свободная энергия Гиббса, скорость испарения, коэффициент испарения, квантовохимическое моделирование

\section{REFERENCES}

1. Tamim J., Hallett W.L.H. A continuous thermodynamics model for multi-component droplet vaporization, Chemical Engineering Science, 50 (1995) 2933.

2. Lippert A.M., Reitz R.D. Modeling of multicomponent fuels using continuous distributions with application to droplet evaporation and sprays, SAE Technical Paper, (1997) 972882.

3. Hallett W.L.H. A simple model for the vaporization of droplets with large numbers of components, Combustion and Flame, 121 (2000) 334.

4. Langmuir I. The dissociation of hydrogen into atoms. [Part II.] Calculation of the degree of dissociation and the heat of formation, J. Am. Chem. Soc., 37 (1915) 417.

5. Langmuir I. The evaporation of small spheres, Phys. Rev., 12 (1918) 368.

6. Houghton H.G. Evaporation of small drops, Physics, 4 (1933) 419.

7. Bradley R.S., Evans M.G., Whytlaw-Gray R.W. The rate of evaporation of droplets. evaporation and diffusion coefficients, and vapour pressures of dibutyl phthalate and butyl stearate, Proceedings of the Royal Society of London A, 186 (1946) 368.

8. Kinzer G.D., Gunn R. The evaporation, temperature and thermal relaxation-time of freely falling waterdrops, J. Meteorology, 8 (1951) 71.

9. Deegan R.D. Pattern formation in drying drops, Phys. Rev. E, 61 (2000) 475.

10. de Gans B.J., Duineveld P.C., Schubert U.S. Inkjet printing of polymers: state of the art and future developments, Advanced Materials, 16 (2004) 203.
11. Dugas V., Broutin J., Souteyrand E. Droplet evaporation study applied to DNA chip manufacturing, Langmuir, 21 (2005) 9130.

12. Wright P.K. 21st Century Manufacturing, Prentice-Hall Inc., New Jersey, 2001.

13. Zhu G.-S., Reitz R.D. A model for highpressure vaporization of droplets of complex liquid mixtures using continuous thermodynamics, Intern. J. Heat and Mass Transfer, 45 (2002) 495.

14. Cao B.-Y., Xie J.-F., Sazhin S.S. Molecular dynamics simulation on evaporation and condensation of $n$-dodecane at liquid-vapour phase equilibria, J. Chem. Phys., 134 (2011) 164309(1-9).

15. Xie J.-F., Sazhin S.S., Cao B.-Y. Molecular dynamics study of the processes in the vicinity of the n-dodecane vapour/liquid interface, Physics of Fluids, 23 (2011) 112104(1-11).

16. Sazhin S.S. Advanced models of fuel droplet heating and evaporation, Progress in Energy and Combustion Science 32 (2006) 162.

17. Chapman S., Cowling T.G. The Mathematical Theory of Nonuniform Gases, Cambridge University Press, Cambridge, 1970, 448 p.

18. Mizuguchi H., Nagayama G., Tsuruta T. Molecular dynamics study on evaporation coefficient of biodiesel fuel, Seventh International Conference on Flow Dynamics, Sendai, Japan, 2010, 386 p.

19. Xie J.-F., Sazhin S.S., Shishkova I.N., Cao B.$Y$. Proceedings of International Symposium on Advances in Computational Heat Transfer (1-6 July, 2012 Bath, UK). CD, Begell House Inc., paper CHT12-MP02 (2012).

20. Xie J.-F., Sazhin S.S., Cao B.-Y. Molecular dynamics study of condensation/evaporation and velocity distribution of $n$-dodecane at 
liquid-vapour phase equilibria, J. Therm. Sci. Techn., 7 (2012) 288.

21. Ortega I. K., Kupiainen O., Kurtén T. et al. From quantum chemical formation free energies to evaporation rates, Atmospheric Chemistry and Physics, 12 (2012) 225.

22. Kupiainen O., Ortega I.K., Kurtén T., Vehkamäki $H$. Amine substitution into sulfuric acid-ammonia clusters, Atmospheric Chemistry and Physics, 12 (2012) 3591.

23. Gun'ko V.M., Nasiri R., Sazhin S.S. et al. A quantum chemical study of the processes during the evaporation of real-life Diesel fuel droplets, Fluid Phase Equilibria, 356 (2013) 146.

24. Gun'ko V. M., Nasiri R., Sazhin S.S. A study of the evaporation and condensation of n-alkane clusters and nanodroplets using quantum chemical methods, Fluid Phase Equilibria, 366 (2014) 99.

25. Sazhin S.S., Al Qubeissi M., Nasiri R. et al. A multi-dimensional quasi-discrete model for the analysis of Diesel fuel droplet heating and evaporation, Fuel, 129 (2014) 238.

26. Chaplin M. Water structure and science, http://www.lsbu.ac.uk/water/.

27. Gun'ko V.M., Turov V.V. Nuclear Magnetic Resonance Studies of Interfacial Phenomena, CRC Press, Boca Raton, 2013.

28. Hunter C.A. Van der Waals interactions in non-polar liquids, Chemical Science 4 (2013) 834.

29. Schleyer P.v.R. (Ed.), Encyclopedia of Computational Chemistry, John Wiley \& Sons, New York, 1998.

30. Atkins P.W., Friedman R. Molecular Quantum Mechanics, Fourth edition, Oxford University Press, Oxford, 2005.

31. COSMOthermX, Version C30_1301, December $12^{\text {th }}$, COSMOlogic $\mathrm{GmbH} \& \mathrm{Co}$. KG, Leverkusen, Germany, 2012.

32. Fujitani Y., Saitoh K., Fushimi A. et al. Effect of isothermal dilution on emission factors of organic carbon and $n$-alkanes in the particle and gas phases of diesel exhaust, Atmospheric Environment, 59 (2012) 389.

33. Dirbude S., Eswaran V., Kushari A. Numerical modelling of droplet evaporation with convection for $n$-alkanes and kerosene fuel, Atomization and Sprays, 21 (2011) 787.

34. Guéna G., Poulard C., Cazabat A.M. Evaporating drops of alkane mixtures, Colloids and Surfaces A: Physicochemical and Engineering Aspects, 298 (2007) 2.

35. Heldmann M., Knorsch T., Wensing $M$. Investigation of fuel atomization and evaporation of a DISI injector spray under homogeneous charge conditions, SAE International J. Engines, 6 (2013) 1213.

36. Zigan L., Schmitz I., Flügel A. et al. Structure of evaporating single- and multicomponent fuel sprays for 2nd generation gasoline direct injection, Fuel, 90 (2011) 348.

37. Frisch M.J., Trucks G.W., Schlegel H.B. et al. Gaussian 09, Revision D.01, Gaussian, Inc., Wallingford CT, 2013.

38. Schmidt M.W., Baldridge K.K., Boatz J.A. et al. General Atomic and Molecular Electronic Structure System, J. Comput. Chem. 14 (1993) 1347.

39. Gordon M.S., Schmidt M.W., In: C.E. Dykstra, G. Frenking, K.S. Kim, G.E. Scuseria (Eds.), Theory and Applications of Computational Chemistry, the First Forty Years, Elsevier, Amsterdam, 2005, 1167-1189 pp..

40. Granovsky A.A. Firefly version 8.1, www http://classic.chem.msu.su/gran/gamess/index. html.

41. Stewart J.J.P. MOPAC 2012, Colorado Springs, CO: Stewart Computational Chemistry, USA, http://openmopac.net/, 2014.

42. Maia J.D.C., Carvalho G.A.U., Mangueira C.P., Jr. et al. GPU linear algebra libraries and GPGPU programming for accelerating MOPAC semiempirical quantum chemistry calculations, J. Chem. Theory Comput., 8 (2012) 3072.

43. Pedretti A., Villa L., Vistoli G. VEGA: an open platform to develop chemo-bio-informatics applications, using plug-in architecture and script programming, Journal of ComputerAided Molecular Design, 18 (2004) 167.

44. Zhurko G.A., Zhurko D.A. Chemcraft (version 1.7, build 375,2013 ), http://www.chemcraftprog.com.

45. Dennington R., Keith T., Millam J. GaussView, Version 5.09, Semichem Inc., Shawnee Mission KS, 2013.

46. Marenich A.V., Cramer C.J., Truhlar D.G. Universal solvation model based on solute electron density and on a continuum model of the solvent defined by the bulk dielectric constant and atomic surface tensions, J. Phys. Chem. B, 113 (2009) 6378. 
47. Yaws C.L. (Ed.) Thermophysical Properties of Chemicals and Hydrocarbons, Norwich, William Andrew Inc., New York, 2008.

48. Adamson A.W., Gast A.P. Physical Chemistry of Surfaces, $6^{\text {th }}$ ed., Wiley, New York, 1997.

49. Xia T.K., Landman U. Molecular evaporation and condensation of liquid n-alkane films, Journal of Chemical Physics, 101 (1994) 2498.

50. Cheeseright T., Mackey M., Rose S., Vinter J. $G$. Molecular field technology applied to virtual screening and finding the bioactive conformation, Expert Opin. Drug Discov., 2 (2007) 131.

51. Honnery D., Nguyen D., Soria J. Microdroplet evaporation under increasing temperature conditions: Experiments and modelling, Fuel, 105 (2013) 247.

52. Frenkel J. Theorie der Adsorption und verwandter Erscheinungen, Zeitschrift für Physik, 26 (1924) 117.

Received 01.07.2014, accepted 26.11.2014 